\title{
Article
}

\section{Effect of post-etch annealing gas composition on the structural and electrochemical properties of Ti2CTX MXene electrodes for supercapacitor applications}

\author{
R. B. Rakhi, Bilal Ahmed, M. N. Hedhili, Dalaver H. Anjum, and H. N. Alshareef
}

Chem. Mater., Just Accepted Manuscript • DOI: 10.1021/acs.chemmater.5b01623 • Publication Date (Web): 08 Jul 2015

Downloaded from http://pubs.acs.org on July 12, 2015

\section{Just Accepted}

\begin{abstract}
"Just Accepted" manuscripts have been peer-reviewed and accepted for publication. They are posted online prior to technical editing, formatting for publication and author proofing. The American Chemical Society provides "Just Accepted" as a free service to the research community to expedite the dissemination of scientific material as soon as possible after acceptance. "Just Accepted" manuscripts appear in full in PDF format accompanied by an HTML abstract. "Just Accepted" manuscripts have been fully peer reviewed, but should not be considered the official version of record. They are accessible to all readers and citable by the Digital Object Identifier (DOI®). "Just Accepted" is an optional service offered to authors. Therefore, the "Just Accepted" Web site may not include all articles that will be published in the journal. After a manuscript is technically edited and formatted, it will be removed from the "Just Accepted" Web site and published as an ASAP article. Note that technical editing may introduce minor changes to the manuscript text and/or graphics which could affect content, and all legal disclaimers and ethical guidelines that apply to the journal pertain. ACS cannot be held responsible for errors or consequences arising from the use of information contained in these "Just Accepted" manuscripts.
\end{abstract}



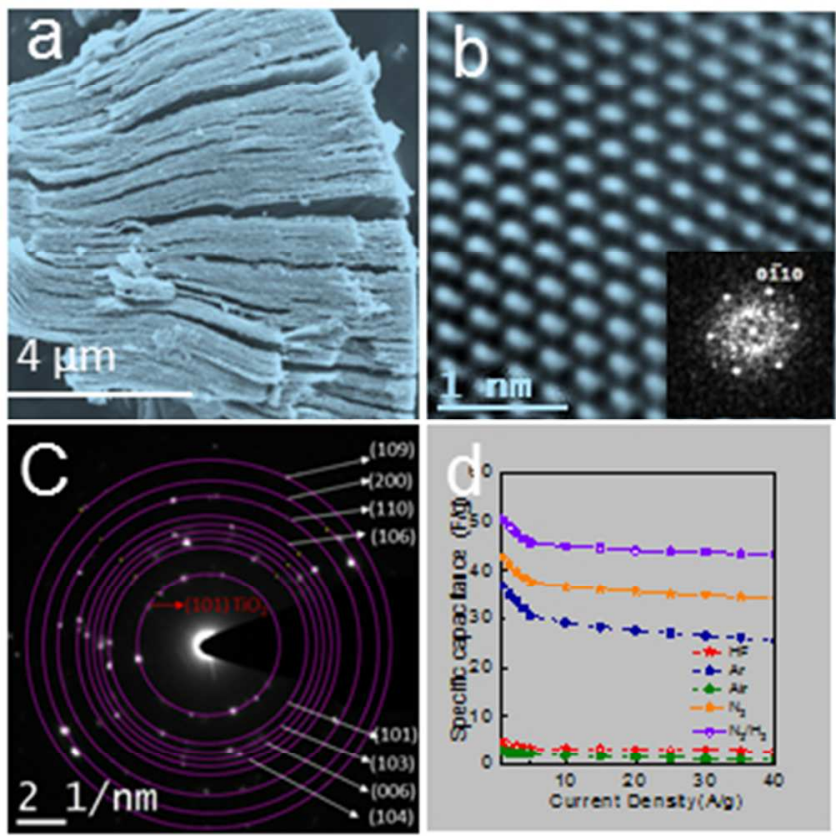

a) SEM image, b) Lattice resolved TEM image (Inset shows the corresponding FFT pattern.), and c) SAED pattern of N2/H2 annealed MXene. d) Specific capacitance of MXene samples at different current densities. $101 \times 101 \mathrm{~mm}$ (96 x 96 DPI) 


\title{
Effect of post-etch annealing gas composition on the structural and electrochemical
} properties of $\mathbf{T i}_{2} \mathbf{C T}_{\mathbf{x}} \mathrm{MXene}$ electrodes for supercapacitor applications

\author{
R. B. Rakhi, Bilal Ahmed, M.N.Hedhili, Dalaver H. Anjum, and H. N.Alshareef* \\ Materials Science and Engineering, King Abdullah University of Science and Technology \\ (KAUST), Thuwal 23955-6900, Saudi Arabia
}

\section{Table of contents}
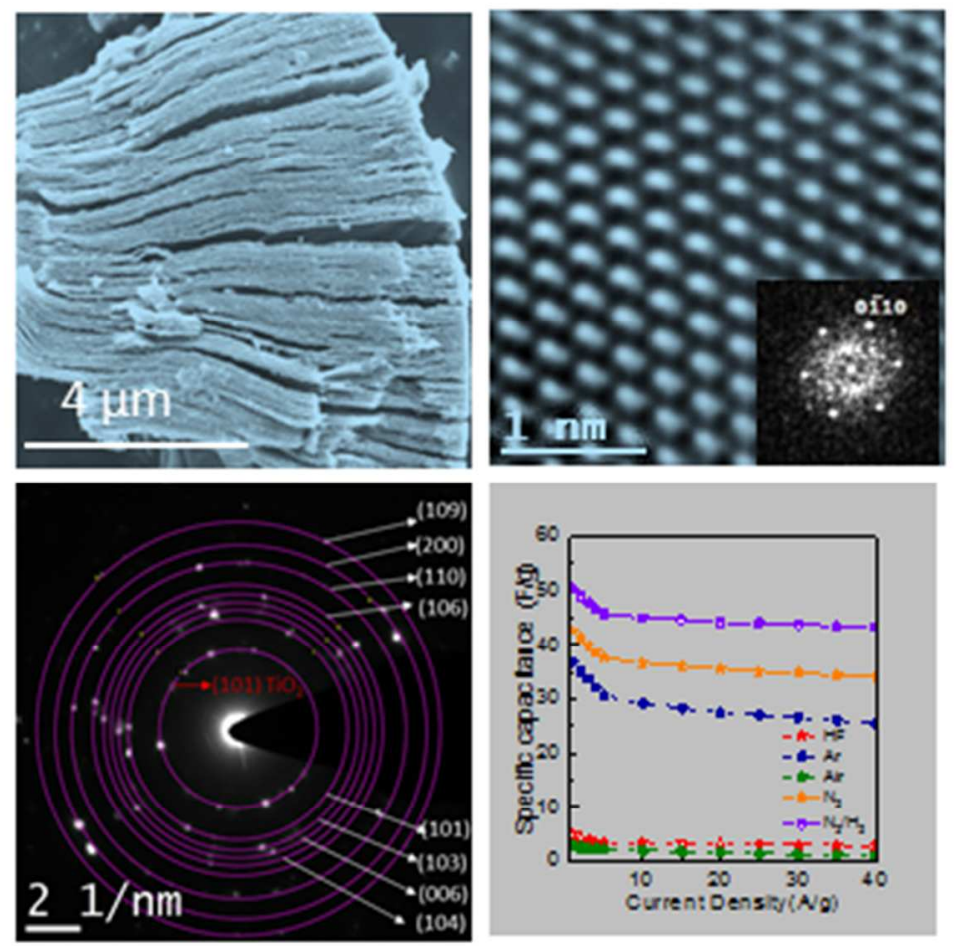

Corresponding author: husam.alshareef@kaust.edu.sa

Phone: Office: +966-(0)2-808-4477 | Cell: +966-(0)5-44700037 


\title{
Effect of post-etch annealing gas composition on the structural and electrochemical properties of $\mathrm{Ti}_{2} \mathrm{CT}_{\mathbf{x}} \mathrm{MXene}$ electrodes for supercapacitor applications
}

\author{
R. B. Rakhi, Bilal Ahmed, M.N.Hedhili, Dalaver H. Anjum, and H. N.Alshareef* \\ Materials Science and Engineering, King Abdullah University of Science and Technology \\ (KAUST), Thuwal 23955-6900, Saudi Arabia
}

\begin{abstract}
Two-dimensional $\mathrm{Ti}_{2} \mathrm{CT}_{\mathrm{x}}$ MXene nanosheets were prepared by the selective etching of Al layer from $\mathrm{Ti}_{2} \mathrm{AlC}$ MAX phase using HF treatment. The MXene sheets retained the hexagonal symmetry of the parent $\mathrm{Ti}_{2} \mathrm{AlC}$ MAX phase. Effect of the post-etch annealing ambient $\left(\mathrm{Ar}, \mathrm{N}_{2}\right.$, $\mathrm{N}_{2} / \mathrm{H}_{2}$ and Air) on the structure and electrochemical properties of the MXene nanosheets was investigated in detail. After annealing in Air, the MXene sheets exhibited variations in structure, morphology and electrochemical properties as compared to HF treated MAX phase. In contrast, samples annealed in Ar, $\mathrm{N}_{2}$ and $\mathrm{N}_{2} / \mathrm{H}_{2}$ ambient retained their original morphology. However, a significant improvement in the supercapacitor performance is observed upon heat treatment in $\operatorname{Ar}, \mathrm{N}_{2}$ and $\mathrm{N}_{2} / \mathrm{H}_{2}$ ambients. When used in symmetric two-electrode configuration, the MXene sample annealed in $\mathrm{N}_{2} / \mathrm{H}_{2}$ atmosphere exhibited the best capacitive performance with specific capacitance value $(51 \mathrm{~F} / \mathrm{g}$ at $1 \mathrm{~A} / \mathrm{g})$ and high rate performance $(86 \%)$. This improvement in the electrochemical performance of annealed samples is attributed to highest carbon content, and lowest fluorine content on the surface of the sample upon annealing, while retaining the original 2D layered morphology, and providing maximum access of aqueous electrolyte to the electrodes.
\end{abstract}

\footnotetext{
*Corresponding author: husam.alshareef@kaust.edu.sa

Phone: Office: +966-(0)2-808-4477 | Cell: +966-(0)5-44700037
} 


\section{INTRODUCTION}

In recent years, MXenes- a new family of 2D early transition metal carbides and carbonitrides, have been receiving significant research interest, by virtue of their excellent electrochemical energy storage properties, good electrical conductivity and superior mechanical properties ${ }^{1-5}$. MXenes are prepared by the selective etching of the A layer from MAX phases, a family of ternary, layered, machinable transition metal carbides, nitrides, and carbonitrides, with a layered hexagonal structure (space group P63/mmc) and chemical composition: $\mathrm{M}_{\mathrm{n}+1} \mathrm{AX}$, where " $\mathrm{M}$ " is an early transition metal, " $\mathrm{A}$ " is an A-group element (mostly groups 13 and 14), " $\mathrm{X}$ " is carbon $(\mathrm{C})$ or nitrogen $(\mathrm{N})$, and $\mathrm{n}=1,2$, or $3 .{ }^{6,7}$ The exfoliated carbides and carbonitrides exhibit structural similarity to exfoliated graphite and hence are termed as MXenes ${ }^{8}$. Cold-pressed discs of different MXene sheets are reported to have good electrical conductivities and hydrophilic behavior $^{6}$. With these unique properties, MXenes are reported to find applications in multiple fields and technologies, such as catalysis, hydrogen storage, electrochemical energy storage/pseudocapacitors, and Li ion batteries. ${ }^{6,9-13}$

The structure and properties of MXenes can be modulated by different physical and chemical treatments $^{14}$. The MXene layers obtained by the selective etching of the MAX phases are usually terminated with either $-\mathrm{OH}$ or $-\mathrm{F}$ or a combination of both. Hence, they can be represented as $M_{n+1} X_{n} T_{x}$, where $T$ stands for the surface termination. It has been reported that the band gap of MXenes can be tuned by changing these surface groups ${ }^{7,15,16}$. In 2012, based on density functional theory computations, Q. Tang and P. Shen reported that dramatic improvement in the theoretical Li-ion specific capacity of $\mathrm{Ti}_{3} \mathrm{C}_{2}$ MXenes can be achieved by the removal of $\mathrm{F}$ groups from the surfaces ${ }^{17}$. It has also been widely reported that $2 \mathrm{D}$ materials like graphene exhibit exceptional sensitivity to their environment. ${ }^{18-20}$ In a recent report, Li et al. stated that heat 
treatment is an efficient way to eliminate the surface groups on MXenes and tune their properties $^{14,21}$. As a new class of graphene like 2D materials, properties of MXenes need to be further explored to get a proper understanding of their fundamental properties ${ }^{22}$. It is of great importance to understand how heating in different ambients influences the morphology, structure and electrochemical properties of MXenes, in order to modulate the structure and properties of MXenes by proper heat treatment processes for various applications ${ }^{6}$. Herein, we report, for the first time, the influence of post-etch annealing ambient on the supercapacitive performance of MXenes. We chose the lightest MXene, $\mathrm{Ti}_{2} \mathrm{CT}_{\mathrm{x}}$ as the representative (as no reports are available on its supercapacitive performance in aqueous electrolytes) and conducted detailed experimental studies on its structural and energy storage properties upon heat treatment in different ambient gases.

\section{EXPERIMENTAL SECTION}

\section{Synthesis of 2-D titanium carbide $\left(\mathrm{Ti}_{2} \mathrm{CT}_{x}\right)$ nanostructures}

Two-dimensional titanium carbide nanosheets were synthesized by exfoliation of commercially available $\mathrm{Ti}_{2} \mathrm{AlC}$ (MAXTHAL 211) powders following similar procedure reported by Naguib et al. . The as-prepared $\mathrm{Ti}_{2} \mathrm{AlC}$ powders were immersed in $10 \% \mathrm{HF}$ for $10 \mathrm{~h}$ at room temperature. The resulting suspension was washed with deionized water for several times and then filtered to get 2D titanium carbide nanosheets (MXenes). The as-prepared MXenes were then annealed at $500 \mathrm{~K}$, in air, $\mathrm{Ar}, \mathrm{N}_{2}$ and $\mathrm{N}_{2} / \mathrm{H}_{2}$ atmosphere for $2 \mathrm{~h}$.

\section{General characterization}

Phase structure of MXene nanosheets were characterized by a powder X-ray diffraction system (XRD, Bruker, D8 ADVANCE) equipped with $\mathrm{Cu} \mathrm{K}_{\alpha}$ radiation $(\lambda=0.15406 \mathrm{~nm})$. Raman 
Spectroscopic measurements were carried out at both room temperature and $100 \mathrm{~K}$, using a Lab Ram Aramis Raman spectrometer with a He-Ne laser having an excitation wavelength of 633 nm. Chemical compositions of the samples were further analyzed using high-resolution X-ray photoelectron spectroscopy (XPS). XPS studies were carried out in a Kratos Axis Ultra DLD spectrometer equipped with a monochromatic Al Ka X-ray source $(\mathrm{h} v=1486.6 \mathrm{eV})$ operating at $150 \mathrm{~W}$, a multichannel plate and delay line detector under a vacuum of $1 \sim 10^{-9} \mathrm{mbar}$. The survey and high-resolution spectra were collected at fixed analyzer pass energies of $160 \mathrm{eV}$ and $20 \mathrm{eV}$, respectively and quantified using empirically derived relative sensitivity factors provided by Kratos Analytical. Samples were mounted in floating mode in order to avoid differential charging. Charge neutralization was required for all samples. Binding energies were referenced to the $\mathrm{C} 1 \mathrm{~s}$ peak of $(\mathrm{C}-\mathrm{C}, \mathrm{C}-\mathrm{H})$ bond which was set at $284.8 \mathrm{eV}$. The data were analyzed with commercially available software, CasaXPS. BET surface area of the samples were determined using surface area and porosimetry system 'Micromeritics' (ASAP 2420) at $77 \mathrm{~K}$. Before measurements, the samples were dried at $70{ }^{\circ} \mathrm{C}$ for $10 \mathrm{~h}$ in a Vacuum oven and then degassed at $150{ }^{\circ} \mathrm{C}$ for $12 \mathrm{~h}$ until the vacuum was less than $2 \mu \mathrm{m} \mathrm{Hg}$. The surface morphology and microstructure of the samples were investigated by a scanning electron microscopy (SEM, FEI Helios NanoLab) and transmission electron microscopy (TEM, FEI Titan).

\section{Electrochemical characterization}

Electrochemical measurements were carried out in symmetric two-electrode configurations using Model 660D electrochemical workstation (CH Instruments). Supercapacitor electrodes of $1.13 \mathrm{~cm}^{2}$ area were prepared using HF treated MAX phase powder and MXene samples annealed at $\mathrm{Ar}, \mathrm{N}_{2}, \mathrm{~N}_{2} / \mathrm{H}_{2}$, and air by the following procedure. The MXene powder was mixed with polytetrafluoroethylene (PTFE) binder and Acetylene Black- which was added to create a conductive network in-between the MXene sheets- in a mass ratio of 90:5:5 and 
dispersed in ethanol. The resulting mixture was homogenized by ultrasonication and coated onto the conductive carbon cloth (ELAT, Nuvant Systems Inc.) substrate, which was followed by drying at $80{ }^{\circ} \mathrm{C}$ for $12 \mathrm{~h}$ in a vacuum oven. Each electrode contained $\sim \mathbf{4} \mathbf{~ m g}$ of MXene. Two symmetric electrodes, separated by a thin polymer separator (Celgard $\left.{ }^{\circledR} 3501\right)$ in 30 wt \% KOH aqueous electrolyte, were sandwiched in a coin cell (CR2032, MTI). Average thickness of active materials in the electrodes was $\sim \mathbf{2 8} \boldsymbol{\mu m}$.

The electrochemical properties of the supercapacitor electrodes were studied by cyclic voltammetry (CV), galvanostatic charge- discharge (CD) and electrochemical impedance spectroscopy (EIS). The CV measurements were conducted in a voltage window between 0 and $0.7 \mathrm{~V}$ at a wide range of scan rates, ranging from $5 \mathrm{mV} / \mathrm{s}$ to $5 \mathrm{~V} / \mathrm{s}$. The $\mathrm{CD}$ measurements were also carried out in the same voltage window under a wide range of current densities, from $1 \mathrm{~A} / \mathrm{g}$ to $40 \mathrm{~A} / \mathrm{g}$. The EIS was performed in the frequency range from $100 \mathrm{k} \mathrm{Hz}$ to $10 \mathrm{~m} \mathrm{~Hz}$ at open circuit voltage by applying a $5 \mathrm{mV}$ signal. All these electrochemical measurements were carried out at room temperature.

Specific capacitance $\left(C_{s p}\right)$ of symmetric supercapacitors were calculated from the cyclic voltammogramms and charge-discharge curves according to Eq. (1) and (2)

$$
C_{s p}=\frac{2 i}{f m}
$$

where ' $i$ ' is average cathodic current of CV loop and ' $f$ ' is the scan rate.

$$
C_{s p}=\frac{2}{m} \times \frac{I}{(\Delta V / \Delta t)}
$$

where ' $I$ ' is the constant current for charge- discharge, $\Delta V / \Delta t$ is slope of the discharge curve. ' $m$ ' is the mass of MXene in one electrode. 


\section{RESULTS AND DISCUSSION}

The XRD patterns of the as-received powder of $\mathrm{Ti}_{2} \mathrm{AlC}$ MAX phase and the exfoliated titanium carbide MXene obtained after HF treatment are shown in Fig. 1a (i) and 1a (ii) respectively. The hexagonal $\mathrm{Ti}_{2} \mathrm{AlC}$ MAX phase powders (JCPDS card no. 00-029-0095) contain small amounts of $\mathrm{Ti}_{3} \mathrm{AlC}_{2}$ (JCPDS card no. 52-0875) as a secondary phase. Considerable loss in crystallinity and structural order is observed in the XRD pattern of the sample after HF treatment. The (002) peak in the MAX phase is broadened and shifted to a lower $2 \theta$ value after $\mathrm{HF}$ treatment, indicating larger d-spacing in the $\mathrm{HF}$ treated sample. The (004) peak of $\mathrm{Ti}_{3} \mathrm{AlC}_{2}$, (secondary phase) also got shifted to a lower angle after HF treatment. XRD pattern of HF treated samples annealed at $250^{\circ} \mathrm{C}$ at different ambients are shown in Fig. 1a(iii-vi).Samples annealed under $\mathrm{Ar}, \mathrm{N}_{2}$, and $\mathrm{N}_{2} / \mathrm{H}_{2}$ atmosphere exhibit patterns similar to that unannealed $\mathrm{HF}$ treated MAX phase (Fig. 1a(ii)). All these samples contain a small amount of anatase $\mathrm{TiO}_{2}$ which was produced by the local heat generated during HF treatment of MAX phase. XRD pattern of air annealed sample clearly shows the complete conversion of the $\mathrm{MXene}$ to anatase $\mathrm{TiO}_{2}$ (JCPDS card no. 00-021-1272) with some graphitic carbon. In order to identify the influence of the annealing atmosphere on the $d$ spacings of the MXene samples, the shift in the (002) peak position is carefully analyzed by repeating the XRD measurements in a smaller range of $2 \theta$ with smaller step size and longer data acquisition time than in Fig. 1 (a) and the results are shown in Fig. 1(b). Due to the insertion of hydroxyl or Flouride groups, the (002) diffraction peak of HF treated sample appears at $2 \theta=11.89^{\circ}$ with an interlayer spacing of $7.43 \AA$. The $(002)$ reflections from samples annealed at $\mathrm{Ar}, \mathrm{N}_{2}$ and $\mathrm{N}_{2} / \mathrm{H}_{2}$ shift to lower $2 \theta$ values $11.82^{\circ}, 11.84^{\circ}$ and $11.79^{\circ}$ respectively. The corresponding interplanar distances are $7.48,7.47$ and $7.50 \AA$ respectively. This clearly indicates that the interlayer spacing of MXenes increases upon heat treatment in different ambients. The interlayer spacing of $\mathrm{N}_{2}-\mathrm{H}_{2}$ is larger than $\mathrm{Ar}$ or $\mathrm{N}_{2}$ annealed samples, 
suggesting removal of more functional groups from the sample. Analysis of these broad peaks indicates the poor order and multilayer character of MXene sheets.

Fig. 1(c) shows the Raman spectra of the HF treated MAX phase $\left(\mathrm{Ti}_{2} \mathrm{CT}_{\mathrm{X} \_} \mathrm{HF}\right)$ sample before and after annealing under different gas ambients. Air annealed sample shows a major peak centered at $150 \mathrm{~cm}-1$ corresponding to anatase $\mathrm{TiO}_{2}$, the intensity of which has been significantly reduced in all the other samples. They exhibit three broad Raman peaks centered nearly around 250,410 , and $610 \mathrm{~cm}^{-1}$, which can be attributed to the vibrations from nonstoichiometric titanium carbide ${ }^{23}$. Further insight to intramolecular interactions in the materials can be obtained from Raman spectroscopy measurements conducted under low temperature. Fig. 1(d) shows the low-temperature Raman spectra of HF treated sample, and that of MXene samples annealed under $\mathrm{Ar}, \mathrm{N}_{2}$, and $\mathrm{N}_{2}-\mathrm{H}_{2}$ atmospheres. As compared to the HF treated sample, the band centered around $610 \mathrm{~cm}^{-1}$ shifts to higher energy for all annealed samples. It has been reported that for layered materials, as the layer thickness decreases, the band position shifts to higher energy representing a slight hardening of the bonds as the layer thickness decreases ${ }^{24}$. Henceforth, the low-temperature Raman spectra indicate a slight thinning of layers in the annealed samples, leading to larger interplanar distance.

XPS investigations were performed to characterize the chemical composition of the surface of the powdered samples and to determine the oxidation state of titanium. Survey spectrum for the powdered sample $\left(\mathrm{Ti}_{2} \mathrm{CT}_{\mathrm{x}_{-}} \mathrm{HF}\right)$ shows that $\mathrm{Ti}, \mathrm{F}, \mathrm{O}$, and $\mathrm{C}$ elements are detected (Figure S 1a). Fig. S1 (b and c) respectively shows the survey spectrum of Air annealed and $\mathrm{N}_{2} / \mathrm{H}_{2}$ annealed MXene samples. The same elements have been detected with different concentrations for all the powdered samples. Atomic concentration of Ti, F, O, and C elements on the surface of the powdered sample are given in Table 1. The results indicate that the sample 
annealed in $\mathrm{N}_{2} / \mathrm{H}_{2}$ atmosphere has the highest Carbon concentration and lowest Fluorine concentration. High-resolution XPS spectra of Ti 2p and C 1s core levels of HF treated sample, and air and $\mathrm{N}_{2} / \mathrm{H}_{2}$ annealed samples are shown in Fig. 2 a, b and c respectively. The Ti $2 p$ core level is fitted with four doublets ( $\operatorname{Ti} 2 p 2 p_{3 / 2}-\operatorname{Ti} 2 p_{1 / 2}$ ) with a fixed area ratio equal to $2: 1$ and doublet separation of $5.7 \mathrm{eV}$. The Ti $2 \mathrm{p}_{3 / 2}$ components were located at $454.5 \mathrm{eV}, 455.9 \mathrm{eV}, 457.4$ $\mathrm{eV}$ and $458.8 \mathrm{eV}$ respectively. The dominant $\mathrm{Ti} 2 \mathrm{p}_{3 / 2}$ component centered at $458.8 \mathrm{eV}$ is associated with $\mathrm{Ti}$ ions with a formal valence $4+{ }^{25}$, while the peak at lower binding energy 457.4 $\mathrm{eV}$ is associated with $\mathrm{Ti}$ ions with reduced charge state $\left(\mathrm{Ti}_{\mathrm{x}} \mathrm{O}_{\mathrm{y}}\right)$. The $\mathrm{Ti} 2 \mathrm{p}_{3 / 2}$ component centered at $454.5 \mathrm{eV}$ corresponds to Ti-C bond ${ }^{26-28}$. This component is absent in the case of air annealed sample. The Ti $2 \mathrm{p}_{3 / 2}$ component centered at $455.9 \mathrm{eV}$ can be assigned to Ti-X peak (a combination of a sub-stoichiometric $\operatorname{TiC}_{x}(x<1)$ and to titanium oxy carbides $\operatorname{TiC}_{\mathrm{x}} \mathrm{O}_{\mathrm{y}}{ }^{29}$. The $\mathrm{C} 1 \mathrm{~s}$ core level of $\mathrm{HF}$ treated sample and $\mathrm{N}_{2} / \mathrm{H}_{2}$ annealed samples (Fig. $2 \mathrm{~d}$ and $\mathrm{f}$ ) are fitted using six components located at $281.2 \mathrm{eV}, 282.1 \mathrm{eV}, 284.8 \mathrm{eV}, 286.4,287.9$ and 288.9 corresponding to $\mathrm{C}-\mathrm{Ti}^{30}{ }^{26}, \mathrm{C}-\mathrm{Ti}-\mathrm{O}, \mathrm{C}-\mathrm{C} / \mathrm{C}-\mathrm{H}, \mathrm{C}-\mathrm{O}, \mathrm{C}=\mathrm{O}{ }^{31,32}$ and $(\mathrm{O}-\mathrm{C}=\mathrm{O}$ and $\mathrm{C}-\mathrm{F})$ bonds ${ }^{32}{ }^{33,}{ }^{34}$ respectively. The components corresponding to $\mathrm{C}-\mathrm{Ti}$ and $\mathrm{C}-\mathrm{Ti}-\mathrm{O}$ were absent in the high resolution $\mathrm{C} 1 \mathrm{~s}$ spectra of the air annealed sample (Fig 2e). High resolution Ti2p and C1s spectra of all the other samples are similar to HF treated sample, with a difference in concentration for different components. XPS studies confirm that upon heat treatment in air, MXene sample gets converted into carbon and $\mathrm{TiO}_{2}$ and samples annealed under $\mathrm{Ar}, \mathrm{N}_{2}$, and $\mathrm{N}_{2} / \mathrm{H}_{2}$ atmosphere retain the initial chemical structure.

The nitrogen adsorption and desorption isotherms of the as-received $\mathrm{Ti}_{2} \mathrm{AlC}$ MAX phase powder, exfoliated $\mathrm{Ti}_{2} \mathrm{CT}_{\mathrm{x}}$ MXene obtained after HF treatment and MXene samples annealed at different ambients, are shown in Figure 3a. The Brunauer-Emmett-Teller (BET) surface area 
values calculated for MAX phase, and HF treated sample are respectively 2.24 and $21.05 \mathrm{~m}^{2} / \mathrm{g}$. The tremendous increase in the surface area of the HF treated sample indicates the successful exfoliation upon the selective etching. The respective BET surface area values of MXene samples annealed at $500{ }^{\circ} \mathrm{C}$ in $\mathrm{Ar}, \mathrm{N}_{2}, \mathrm{~N}_{2} / \mathrm{H}_{2}$, and air are $21.17,22.44,23.89$ and $27.45 \mathrm{~m}^{2} / \mathrm{g}$. All the annealed samples exhibit distinct hysteresis loops in the range of $0.45-1.0 \mathrm{P} / \mathrm{P}_{0}$, which suggests the presence of a mesoporous structure. BET surface area values obtained for the MXene samples in the present study agree well with the available literature ${ }^{14}$. MXene samples annealed in $\mathrm{Ar}, \mathrm{N}_{2}$, and $\mathrm{N}_{2} / \mathrm{H}_{2}$, atmosphere exhibit higher surface areas as compared to the $\mathrm{HF}$ treated sample, which may be due to the increase in the interplanar distance upon annealing. The pore size distributions of the samples calculated by desorption isotherms using Barret-JoynerHalenda (BJH) method are shown in Figure 3b. BJH Desorption cumulative volume of pores between $1.70 \mathrm{~nm}$ and $300.00 \mathrm{~nm}$ diameter for the MAX phase, HF treated sample and the MXene samples annealed at $\mathrm{Ar}, \mathrm{N}_{2}, \mathrm{~N}_{2} / \mathrm{H}_{2}$, and air ambients are 0.0136, 0.0474, 0.0511, 0.0547, 0.0634 , and $0.0930 \mathrm{~cm}^{3} / \mathrm{g}$ respectively.

SEM images of HF treated MAX phase, and MXene samples annealed in $\mathrm{N}_{2} / \mathrm{H}_{2}$ and air are shown in Fig. 3 a, b, and c respectively. It is evident from Fig. 3a that the HF treatment results in the removal of the $\mathrm{Al}$ layer from the $\mathrm{Ti}_{2} \mathrm{AlC}$ MAX phase, resulting in stacked MXene sheets resembling exfoliated graphite ${ }^{35}$. EDAX pattern of HF treated sample (Fig. S2) further confirms the removal of $\mathrm{Al}$, but ensures the presence of $\mathrm{F}$ and $\mathrm{O}$, indicating the possible surface termination in the exfoliated nanosheets with F, OH and/or O groups. Some blisters are observed on the edges and surfaces of the exfoliated nanosheets, which may be due to the bubbles liberated due to the release of $\mathrm{H}_{2}$ gas during the HF treatment of the MAX phase. ${ }^{6}$ There is no visible change in the morphology of MXene samples after heat treatment in Ar or $\mathrm{N}_{2}$ or $\mathrm{N}_{2} / \mathrm{H}_{2}$ 
atmosphere. But the sample annealed in air (Fig. 3C) undergoes a complete change in its morphology and it consists of nanosheets composed of numerous $\mathrm{TiO}_{2}$ nanocrystals on thin graphitic nanosheets similar to the ones reported by Naguib et al.. ${ }^{19}$

TEM and HRTEM analyses were used to investigate the microstructure of MXene nanosheets in detail. TEM images of HF treated MAX phase nanosheets, and that of MXenes annealed in $\mathrm{Ar}, \mathrm{N}_{2}$, and $\mathrm{N}_{2} / \mathrm{H}_{2}$ atmosphere are shown in Fig. 5 a, b, c, and d respectively. Stacked multilayer nature of MXene sheets is evident from Fig. $5 \mathrm{a}$ and $\mathrm{b}$. The individual MXene sheets are found to be extremely thin and transparent. These sheets have many nanometer-sized holes similar to those reported for functionalized graphene.

High-resolution TEM images of etched MXene nanosheets in $\mathrm{N}_{2} / \mathrm{H}_{2}$ annealed MXene sample are shown in Fig. $6 \mathrm{a}$ and b. The lattice resolved HRTEM image of a single exfoliated MXene sheet with the correseponding FFT pattern is shown in Fig. 6 c. Selected area diffraction (SAED) pattern (Fig. 6 d) of the MXene sheets demonstrates that the MXene sheets retain the hexagonal symmetry and crystallinity of the basal planes of the parent $\mathrm{Ti}_{2} \mathrm{AlC}$ MAX phase. There is one reflection peak corresponding to $\mathrm{TiO}_{2}$, which was produced by the local heat developed at the time of etching of the MAX phase. Energy-dispersive spectrometer (EDS) elemental mapping was employed to study the spatial distribution of the elements $\mathrm{Ti}, \mathrm{C}$, and $\mathrm{O}$ in MXene samples. Fig. S3 (a and b) shows the results obtained for HF treated MAX phase, and $\mathrm{N}_{2} / \mathrm{H}_{2}$ annealed MXene samples, respectively. The elemental mapping of $\mathrm{O}$ showing the spatial distribution of oxygen in nanosheet and $\mathrm{N}_{2} / \mathrm{H}_{2}$ annealed sample (Fig. $\mathbf{S 3}$ b (iv)), indicates that oxygen is present mainly at the edges of the MXene sheet.

MXene sample annealed in air undergoes a completed transformation in its micro structure and morphology as evident from the TEM and HRTEM images shown in Fig. 7. TEM 
image $7 \mathrm{a}$ indicates that the sample contains nanocrystals and thin nanosheets. HRTEM image of the nanocrystals and their corresponding SAED pattern are shown in Fig. 7c and e respectively. The SAED pattern indicates the polycrystalline structure of the sample. SAED pattern can be indexed to the Body-centered tetragonal anatase $\mathrm{TiO}_{2}$ crystal structure using Circular Hough Diffraction Analysis. ${ }^{36}$ SAED pattern (Fig. 7f) corresponding to the TEM images of the nanoflakes (Fig. 7d) can be indexed to graphitic carbon. The TEM results agree well with the PXRD and Raman Spectroscopy results.

Symmetric button cell supercapacitors were fabricated using electrodes based on HF treated MAX phase and MXene samples annealed under $\mathrm{Ar}, \mathrm{N}_{2}, \mathrm{~N}_{2} / \mathrm{H}_{2}$, and air atmosphere and the electrochemical measurements were conducted, in order to investigate the possible influence of the annealing ambient on the electrochemical performance. Fig. 8(a-e) respectively shows CV loops obtained for symmetric button cell supercapacitors based on HF treated MAX phase and MXene samples annealed under $\mathrm{Ar}, \mathrm{N}_{2}, \mathrm{~N}_{2} / \mathrm{H}_{2}$, and air atmosphere at different scan rates of 5,10, 20,50 and $100 \mathrm{mV} / \mathrm{s}$ in a fixed potential range of 0-0.7 V. All the test cells except the one based on air annealed sample retain nearly rectangular CV loops, up to a scan rate of $100 \mathrm{mV} / \mathrm{s}$, which are characteristics for supercapacitors with excellent capacitance behavior and low contact resistance. These devices are able to retain the rectangular shape of the CV curves even at a very high scan rate of $1 \mathrm{~V} / \mathrm{s}$ (Fig. S4). From Fig. S5, it is clear that these supercapacitor devices could also exhibit triangular galvanostatic charge-discharge curves at different constant current densities confirming excellent capacitive behavior. Deviation from supercapacitive behavior of the supercapacitor based on air annealed sample (Fig. 8e and S5e) as compared to other samples can be attributed to the pseudocapacitive behavior of the nanocrystalline $\mathrm{TiO}_{2}$ particles. 
A comparison of CV loops of symmetric supercapacitors based on HF treated MAX phase and MXene samples annealed under $\mathrm{Ar}, \mathrm{N}_{2}, \mathrm{~N}_{2} / \mathrm{H}_{2}$, and air atmosphere at a scan rate of 20 $\mathrm{mV} / \mathrm{s}$ is shown in Fig. 9a. For the same mass loading, the CV curves show different areas indicating different levels of stored charge. From the CV loops specific capacitances of 4.2, 28.1, 39.7, 47.4 and 2.4 F/g respectively (using equations (1) and (3)) are obtained for the HF treated MAX phase and MXene samples annealed at $\mathrm{Ar}, \mathrm{N}_{2}, \mathrm{~N}_{2} / \mathrm{H}_{2}$, and air atmosphere. Fig. $9 \mathrm{~b}$ shows the comparison of galvanostatic charge-discharge curves for the samples at a constant current density of $1 \mathrm{~A} / \mathrm{g}$. The constant current charge-discharge curves of all the devices are nearly triangular, with reduced internal resistance at the beginning of the discharge curve. The reduction in internal resistance may be attributable to the excellent contact of the active materials to the conducting carbon cloth substrate. Supercapacitor based on exfoliated (HF treated) MAX phase exhibited a small specific capacitance value of $4.9 \mathrm{~F} / \mathrm{g}$. A tremendous improvement in the supercapacitive performance is obtained by annealing at $\mathrm{Ar}, \mathrm{N}_{2}$ and $\mathrm{N}_{2} / \mathrm{H}_{2}$ atmosphere. The specific capacitance values for the supercapacitors based on samples annealed under Ar, N2 and $\mathrm{N}_{2} / \mathrm{H}_{2}$ ambients are respectively $36.9,42.8$ and $50.5 \mathrm{~F} / \mathrm{g}$. Variations in specific capacitances of symmetric supercapacitors with increase in scan rate and current density are shown in Fig. 9c and $\mathrm{d}$ respectively. At lower scan rates (below $20 \mathrm{mV} / \mathrm{s}$ )/current densities (below $5 \mathrm{~A} / \mathrm{g}$ ), the specific capacitance decreases with the increase in scan rate/ current density and after that the specific capacitance tends to stabilize. At lower scan rate/discharge current density, electrolyte ions can penetrate into the inner structure of the entire electrode giving rise to the maximum capacitive performance. For 2D materials like MXene, it has been reported that the spontaneous intercalation of cation from the aqueous electrolyte solutions makes an important contribution to the total specific capacitance. The intercalation phenomena readily takes place in basic 
electrolytes like $\mathrm{KOH}$, used in the present study. ${ }^{11}$ Among the different supercapacitors, symmetric supercapacitor based on MXene sample annealed under $\mathrm{N}_{2} / \mathrm{H}_{2}$ atmosphere exhibited the best supercapacitive performance with a maximum specific capacitance of $51 \mathrm{~F} / \mathrm{g}$ at a scan rate of $5 \mathrm{mV} / \mathrm{s}$. The rate performance calculated at a very high current density of $40 \mathrm{~A} / \mathrm{g}$ for the different supercapacitor devices based on for the HF treated MAX phase and MXene samples annealed under $\mathrm{Ar}, \mathrm{N}_{2}, \mathrm{~N}_{2} / \mathrm{H}_{2}$, and air atmosphere are $64 \%, 69 \%, 80 \%, 86 \%$ and 35\%. Air annealed MXene sample, which underwent complete structural and morphological transformation exhibited the poorest supercapacitive performance. Fig. 9e shows the Ragone plot (power density vs. energy density) of the different symmetric supercapacitors test cells. The energy $(E)$ and power densities (P) for the supercapacitors were calculated from chargedischarge curves at different current densities using equations (5) and (6) respectively.

$$
E=\frac{1}{2} C_{s p} \Delta V^{2}
$$

where ' $\Delta V$ ' is the potential window of discharge process.

$$
P=E / \Delta t
$$

At a constant power density of $20 \mathrm{~kW} / \mathrm{kg}$, the energy densities obtained for supercapacitors based on HF treated sample and MXene samples annealed at $\mathrm{Ar}, \mathrm{N}_{2}, \mathrm{~N}_{2} / \mathrm{H}_{2}$, and air atmosphere are $0.211,1.811,2.375,2.988$ and $0.089 \mathrm{Wh} / \mathrm{kg}$ respectively. At a low power density of $0.7 \mathrm{~kW} / \mathrm{kg}$, the energy densities reach as high as $0.335,2.511,2.913,3.437$, and 0.209 $\mathrm{Wh} / \mathrm{kg}$ respectively for the test cells. From the analysis of Ragone plot, it is evident that MXene sample annealed under $\mathrm{N}_{2} / \mathrm{H}_{2}$ atmosphere works as a very promising EDLC electrode material. In comparison with all other MXene samples, $\mathrm{N}_{2} / \mathrm{H}_{2}$ annealed sample maintains high power density without much reduction in energy density. Cyclic stability curves for symmetric 
supercapacitors at a constant current density of $1 \mathrm{~A} / \mathrm{g}$ are illustrated in Fig. $9 \mathrm{f}$. At the end of 6000 cycles, supercapacitors based on HF treated MAX phase and MXene samples annealed under $\mathrm{Ar}, \mathrm{N}_{2}, \mathrm{~N}_{2} / \mathrm{H}_{2}$, and air atmosphere retain respectively $87 \%, 94 \%, 92 \%, 93 \%$ and $86 \%$ of their maximum capacitance.

Fig. 10a shows the experimental EIS spectra (Nyquist plot) for symmetric supercapacitors based on HF treated sample and MXene samples annealed under $\mathrm{Ar}, \mathrm{N}_{2}, \mathrm{~N}_{2} / \mathrm{H}_{2}$, and air atmosphere. The impedance spectra can be divided into two regions by the so-called knee frequency, with a semicircle arc in the high-frequency region and a straight line in the lowfrequency region. The real axis intercept at high-frequency corresponds to the uncompensated resistance of the bulk electrolyte solution $\left(R_{S}\right)$, and it is also known as the equivalent series resistance (ESR). The magnitude of ESR obtained from the $x$-intercept of the Nyquist plot for supercapacitors based on HF treated MAX phase, and MXene samples annealed under Ar, $\mathrm{N}_{2}$, $\mathrm{N}_{2} / \mathrm{H}_{2}$, and air atmosphere are $1.23,1.01,1.08,1.03$, and $1.10 \Omega$ respectively. These lower values indicate consistent interfacial contact between the active materials and the carbon substrates. The diameter of the semicircle in the high frequency range gives the value of charge transfer resistance $\left(R_{c t}\right) . R_{c t}$ is a surface property of the porous electrode which is related to the electroactive surface area. It is a combination of electrolyte accessible area and electrical conductivity of the electrode material. The larger the electroactive surface area, the lower the charge-transfer resistance. The line in the low-frequency region making an angle $45^{\circ}$ with the real axis, is the Warburg line which is a result of the frequency dependence of ion diffusion in the electrolyte to the electrode interface. Fig. $10 \mathrm{~b}$ presents the frequency response of specific capacitance obtained from EIS measurements of supercapacitors based on HF treated MAX 
phase, and MXene samples annealed at $\mathrm{Ar}, \mathrm{N}_{2}, \mathrm{~N}_{2} / \mathrm{H}_{2}$, and air atmosphere. The instrument's (CHI 660D) limitations in the EIS measurements results in the steps on the frequency plots. The capacitance values were obtained from the following Eq. (7)

$$
C=-\frac{1}{2 \pi f z^{\prime \prime}}
$$

Here, $C$ is the cell capacitance, $f$ is the frequency, $z^{\prime \prime}$ is the imaginary part of impedance. When the frequency increases, the capacitance of all samples decreases. At a frequency of $1 \mathrm{~Hz}$, the capacitors retain nearly half of its maximum capacitance (@0.01 Hz). At high frequency region above $1000 \mathrm{~Hz}$ the supercapacitors behave like a pure resistance.

From the present study, it is evident that the annealing ambient plays a crucial role in tuning the structure, morphology and capacitive performance of 2-D $\mathrm{Ti}_{2} \mathrm{CT}_{\mathrm{x}}$ MXene nanosheets. Annealing in air transforms $\mathrm{MXenes}$ to $\mathrm{TiO}_{2}$ nanoparticles and graphitic carbon and brings down the capacitive performance. Annealing in $\mathrm{Ar}, \mathrm{N}_{2}$ and $\mathrm{N}_{2} / \mathrm{H}_{2}$ atmosphere improves the supercapacitive performance. This can be attributed to the increase in surface area and increase in interplanar distance in the annealed sample as explained in Fig. 1 and 3. MXene sample annealed in $\mathrm{N}_{2} / \mathrm{H}_{2}$ atmosphere exhibits superior supercapacitive performance as compared to other samples. A valid explanation for this behavior can be given based on XPS results (Table 1). From Table 1 and Fig. S1, it is evident that the surface layers of $\mathrm{N}_{2} / \mathrm{H}_{2}$ annealed sample contains the highest amount carbon and lowest amount of Fluorine. The maximum carbon content ensures high conductivity of the electrode and improves the supercapacitor performance. Moreover, the reduction in the concentration of Fluoride ion brings improvement in the specific capacitance. 


\title{
CONCLUSION
}

In summary, we have demonstrated that post-etch annealing ambient of $2 \mathrm{D} \mathrm{Ti}_{2} \mathrm{CT}_{\mathrm{x}} \mathrm{MXenes}$ plays a significant role in tuning their structure, surface termination, and electrochemical properties. Annealing in air results in transformation of $\mathrm{MXene}$ to $\mathrm{TiO}_{2}$ nanoparticles and graphitic carbon. The MXene sample annealed in $\mathrm{N}_{2} / \mathrm{H}_{2}$ atmosphere exhibited best performance with specific capacitance values of $51 \mathrm{~F} / \mathrm{g}$ at $1 \mathrm{~A} / \mathrm{g}$, high rate performance $(86 \%$ ) (current densities ranging from $1 \mathrm{~A} / \mathrm{g}$ to $40 \mathrm{~A} / \mathrm{g}$ ) and excellent cycling stability (93\% after 6000 chargedischarge cycles) when used in symmetric two-electrode configuration. This improvement in the performance was attributed to highest carbon content, and lowest fluorine content on the surface of the sample upon annealing, while retaining the original 2D layered morphology, and providing maximum access of aqueous electrolyte to the electrodes.

\author{
AUTHOR INFORMATION \\ Corresponding Author \\ *Phone: +966-(0)12-808-4477. E-mail: husam.alshareef@kaust. edu.sa. \\ Notes \\ The authors declare no competing financial interest.
}

\section{ACKNOWLEDGEMENTS}

Research reported in this manuscript has been supported by King Abdullah University of Science \& Technology. Authors thank the -'Advanced nanofabrication, Imaging and Characterization Laboratory' and 'Analytic Core Laboratory', at KAUST.

\section{SUPPORTING INFORMATION}


XPS survey spectra of different MXene samples, EDAX pattern of the HF treated MXene sample, Elemental mapping, CV curves and galvanostatic charge discharge curves of different MXene samples. This information is available free of charge via the Internet at http://pubs.acs.org.

\section{REFERENCES}

1. Ling, Z.; Ren, C. E.; Zhao, M.-Q.; Yang, J.; Giammarco, J. M.; Qiu, J.; Barsoum, M. W.; Gogotsi, Y., Flexible and conductive MXene films and nanocomposites with high capacitance. Proceedings of the National Academy of Sciences of the United States of America 2014, 111, 16676-16681.

2. Kurtoglu, M.; Naguib, M.; Gogotsi, Y.; Barsoum, M. W., First principles study of two-dimensional early transition metal carbides. MRS Communications 2012, 2, 133-137.

3. Er, D.; Li, J.; Naguib, M.; Gogotsi, Y.; Shenoy, V. B., Ti3C2 MXene as a high capacity electrode material for metal (Li, Na, K, Ca) ion batteries. ACS Appl Mater Interfaces 2014, 6, 11173-9.

4. Xie, Y.; Dall'Agnese, Y.; Naguib, M.; Gogotsi, Y.; Barsoum, M. W.; Zhuang, H. L.; Kent, P. R., Prediction and characterization of MXene nanosheet anodes for non-lithium-ion batteries. ACS Nano 2014, 8, 9606-15.

5. Khazaei, M.; Arai, M.; Sasaki, T.; Chung, C.-Y.; Venkataramanan, N. S.; Estili, M.; Sakka, Y.; Kawazoe, Y., Novel Electronic and Magnetic Properties of Two-Dimensional Transition Metal Carbides and Nitrides. Advanced Functional Materials 2013, 23, 2185-2192.

6. Naguib, M.; Mashtalir, O.; Carle, J.; Presser, V.; Lu, J.; Hultman, L.; Gogotsi, Y.; Barsoum, M. W., Two-Dimensional Transition Metal Carbides. Acs Nano 2012, 6, 1322-1331.

7. Naguib, M.; Mochalin, V. N.; Barsoum, M. W.; Gogotsi, Y., 25th Anniversary Article: MXenes: A New Family of Two-Dimensional Materials. Advanced Materials 2014, 26, 992-1005.

8. Naguib, M.; Kurtoglu, M.; Presser, V.; Lu, J.; Niu, J.; Heon, M.; Hultman, L.; Gogotsi, Y.; Barsoum, M. W., Two-Dimensional Nanocrystals Produced by Exfoliation of Ti3AIC2. Advanced Materials 2011, 23, 4248-4253.

9. Naguib, M.; Kurtoglu, M.; Presser, V.; Lu, J.; Niu, J.; Heon, M.; Hultman, L.; Gogotsi, Y.; Barsoum, M. W., Two-Dimensional Nanocrystals Produced by Exfoliation of Ti3AIC2. Advanced Materials 2011, 23, 4248-4253.

10. Hu, Q.; Sun, D.; Wu, Q.; Wang, H.; Wang, L.; Liu, B.; Zhou, A.; He, J., MXene: A New Family of Promising Hydrogen Storage Medium. Journal of Physical Chemistry A 2013, 117, 14253-14260.

11. Lukatskaya, M. R.; Mashtalir, O.; Ren, C. E.; Dall'Agnese, Y.; Rozier, P.; Taberna, P. L.; Naguib, M.; Simon, P.; Barsoum, M. W.; Gogotsi, Y., Cation Intercalation and High Volumetric Capacitance of TwoDimensional Titanium Carbide. Science 2013, 341, 1502-1505.

12. Mashtalir, O.; Naguib, M.; Mochalin, V. N.; Dall'Agnese, Y.; Heon, M.; Barsoum, M. W.; Gogotsi, Y., Intercalation and delamination of layered carbides and carbonitrides. Nature Communications 2013, 4, 1716.

13. Lee, Y.; Cho, S. B.; Chung, Y. C., Tunable indirect to direct band gap transition of monolayer Sc2CO2 by the strain effect. ACS Appl Mater Interfaces 2014, 6, 14724-8. 
14. Naguib, M.; Come, J.; Dyatkin, B.; Presser, V.; Taberna, P.-L.; Simon, P.; Barsoum, M. W.; Gogotsi, Y., MXene: a promising transition metal carbide anode for lithium-ion batteries. Electrochemistry Communications 2012, 16, 61-64.

15. Ma, Z.; Hu, Z.; Zhao, X.; Tang, Q.; Wu, D.; Zhou, Z.; Zhang, L., Tunable Band Structures of Heterostructured Bilayers with Transition-Metal Dichalcogenide and MXene Mono layer. Journal of Physical Chemistry C 2014, 118, 5593-5599.

16. Tang, Q.; Zhou, Z., Graphene-analogous low-dimensional materials. Progress in Materials Science 2013, 58, 1244-1315.

17. Tang, Q.; Zhou, Z.; Shen, P., Are MXenes Promising Anode Materials for Li lon Batteries? Computational Studies on Electronic Properties and Li Storage Capability of Ti3C2 and Ti3C2X2 (X = F, $\mathrm{OH})$ Monolayer. Journal of the American Chemical Society 2012, 134, 16909-16916.

18. Tang, Q.; Zhou, Z.; Shen, P., Are MXenes Promising Anode Materials for Li lon Batteries? Computational Studies on Electronic Properties and Li Storage Capability of Ti3C2 and Ti3C2X2 (X = F, $\mathrm{OH})$ Monolayer. Journal of the American Chemical Society 2012, 134, 16909-16916.

19. Naguib, M.; Mashtalir, O.; Lukatskaya, M. R.; Dyatkin, B.; Zhang, C.; Presser, V.; Gogotsi, Y.; Barsoum, M. W., One-step synthesis of nanocrystalline transition metal oxides on thin sheets of disordered graphitic carbon by oxidation of MXenes. Chemical Communications 2014, 50, 7420-7423. 20. Sun, D.; Hu, Q.; Chen, J.; Zhou, A., First Principles Calculations of the Relative Stability, Structure and Electronic Properties of Two Dimensional Metal Carbides and Nitrides. In High-Performance Ceramics Viii, Pts 1 and 2, Pan, W.; Gong, J., Eds. 2014; Vol. 602-603, pp 527-531.

21. Li, Z.; Wang, L.; Sun, D.; Zhang, Y.; Liu, B.; Hu, Q.; Zhou, A., Synthesis and thermal stability of two-dimensional carbide MXene Ti3C2. Materials Science and Engineering B-Advanced Functional SolidState Materials 2015, 191, 33-40.

22. Xie, Y.; Naguib, M.; Mochalin, V. N.; Barsoum, M. W.; Gogotsi, Y.; Yu, X.; Nam, K.-W.; Yang, X.-Q.; Kolesnikov, A. I.; Kent, P. R. C., Role of Surface Structure on Li-Ion Energy Storage Capacity of TwoDimensional Transition-Metal Carbides. Journal of the American Chemical Society 2014, 136, 6385-6394. 23. Cai, K. J.; Zheng, Y.; Shen, P.; Chen, S. Y., TiCx-Ti2C nanocrystals and epitaxial graphene-based lamellae by pulsed laser ablation of bulk TiC in vacuum. Crystengcomm 2014, 16, 5466-5474.

24. Hodkiewicz, J., Characterizing Graphene with Raman Spectroscopy. Thermoscientific Application Note 2010, 51946.

25. Biesinger, M. C.; Lau, L. W. M.; Gerson, A. R.; Smart, R. S. C., Resolving surface chemical states in XPS analysis of first row transition metals, oxides and hydroxides: Sc, Ti, V, Cu and Zn. Applied Surface Science 2010, 257, 887-898.

26. Dang, B. H. Q.; Rahman, M.; MacElroy, D.; Dowling, D. P., Evaluation of microwave plasma oxidation treatments for the fabrication of photoactive un-doped and carbon-doped TiO2 coatings. Surface \& Coatings Technology 2012, 206, 4113-4118.

27. Hassan, M.; Rawat, R. S.; Lee, P.; Hassan, S. M.; Qayyum, A.; Ahmad, R.; Murtaza, G.; Zakaullah, M., Synthesis of nanocrystalline multiphase titanium oxycarbide (TiCxOy) thin films by UNU/ICTP and NX2 plasma focus devices. Applied Physics a-Materials Science \& Processing 2008, 90, 669-677.

28. Ottakam Thotiyl, M. M.; Freunberger, S. A.; Peng, Z.; Chen, Y.; Liu, Z.; Bruce, P. G., A stable cathode for the aprotic Li-O2 battery. Nature materials 2013, 12, 1050-6.

29. Zhang, S.; Fu, Y. Q.; Bui, X. L.; Du, H. J., XPS study of diamond-like carbon-based nanocomposite films. 2004; Vol. 3, p 797-802.

30. Liu, G.; Han, C.; Pelaez, M.; Zhu, D.; Liao, S.; Likodimos, V.; loannidis, N.; Kontos, A. G.; Falaras, P.; Dunlop, P. S. M.; Byrne, J. A.; Dionysiou, D. D., Synthesis, characterization and photocatalytic evaluation of visible light activated C-doped TiO2 nanoparticles. Nanotechnology 2012, 23, 294003. 
31. Dong, F.; Wang, H.; Wu, Z., One-Step "Green" Synthetic Approach for Mesoporous C-Doped Titanium Dioxide with Efficient Visible Light Photocatalytic Activity. Journal of Physical Chemistry C 2009, $113,16717-16723$.

32. Zhang, L.; Chen, G.; Hedhili, M. N.; Zhang, H.; Wang, P., Three-dimensional assemblies of graphene prepared by a novel chemical reduction-induced self-assembly method. Nanoscale 2012, 4 , 7038-7045.

33. Touhara, H.; Okino, F., Property control of carbon materials by fluorination. Carbon 2000, 38, 241-267.

34. Zhang, F.-Y.; Advani, S. G.; Prasad, A. K.; Boggs, M. E.; Sullivan, S. P.; Beebe, T. P., Jr., Quantitative characterization of catalyst layer degradation in PEM fuel cells by $\mathrm{X}$-ray photoelectron spectroscopy. Electrochimica Acta 2009, 54, 4025-4030.

35. Viculis, L. M.; Mack, J. J.; Mayer, O. M.; Hahn, H. T.; Kaner, R. B., Intercalation and exfoliation routes to graphite nanoplatelets. Journal of Materials Chemistry 2005, 15, 974-978.

36. Mitchell, D. R. G., Circular Hough transform diffraction analysis: A software tool for automated measurement of selected area electron diffraction patterns within Digital Micrograph (TM).

Ultramicroscopy 2008, 108, 367-374.

Table 1: Atomic concentration of elements in surface layers of HF treated MAX phase and MXene samples annealed under $A r, \mathrm{~N}_{2}$ and $\mathrm{N}_{2} / \mathrm{H}_{2}$ and air atmosphere

\begin{tabular}{|l|c|c|c|c|c|}
\hline Sample & & & & & \\
& Ti & $\mathbf{O}$ & $\mathbf{C}$ & $\mathbf{F}$ & $\mathbf{N}$ \\
\hline HF Treated & 25.9 & 30.9 & 35.7 & 6.8 & 0.7 \\
\hline Ar annealed & 25.4 & 31.0 & 37.6 & 5.5 & 0.5 \\
\hline $\mathbf{N}_{\mathbf{2}}$ annealed & 26.6 & 31.1 & 36.4 & 4.9 & 0.9 \\
\hline $\mathbf{N}_{\mathbf{2}}$ /H2 nnealed & 16.7 & 22.9 & $\mathbf{5 6 . 8}$ & 3.4 & 0.3 \\
& & & & & \\
\hline
\end{tabular}




\begin{tabular}{|l|l|l|l|l|l|}
\hline Air annealed & 21.0 & 40.9 & 31.1 & 6.2 & 0.8 \\
\hline
\end{tabular}

\section{Figures}
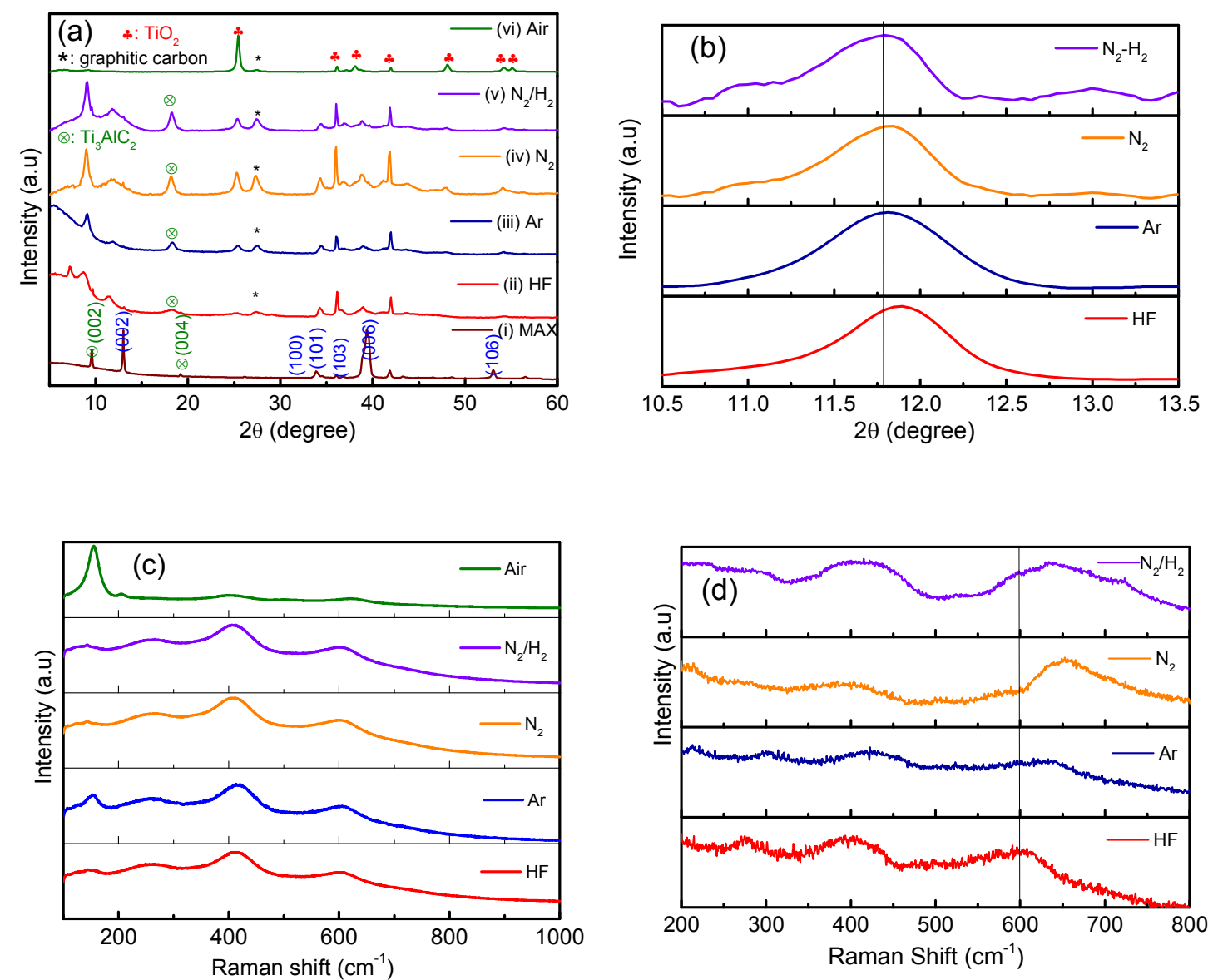

Figure 1: (a) PXRD pattern of MAX phase and different MXene samples, (b) PXRD pattern of $\mathrm{HF}$ treated MAX phase and $\mathrm{Ar}, \mathrm{N}_{2}$ and $\mathrm{N}_{2} / \mathrm{H}_{2}$ annealed MXene samples over a 

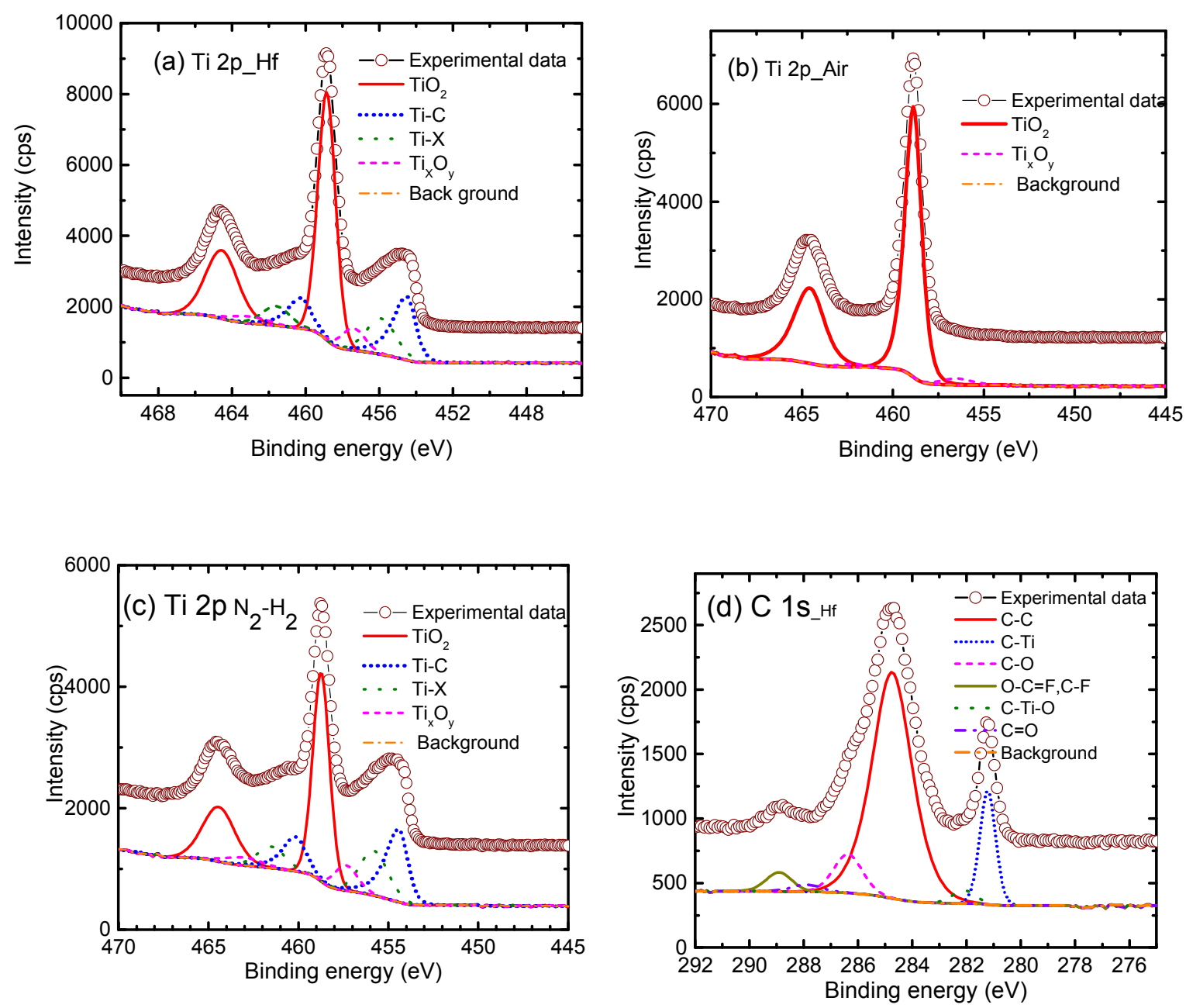

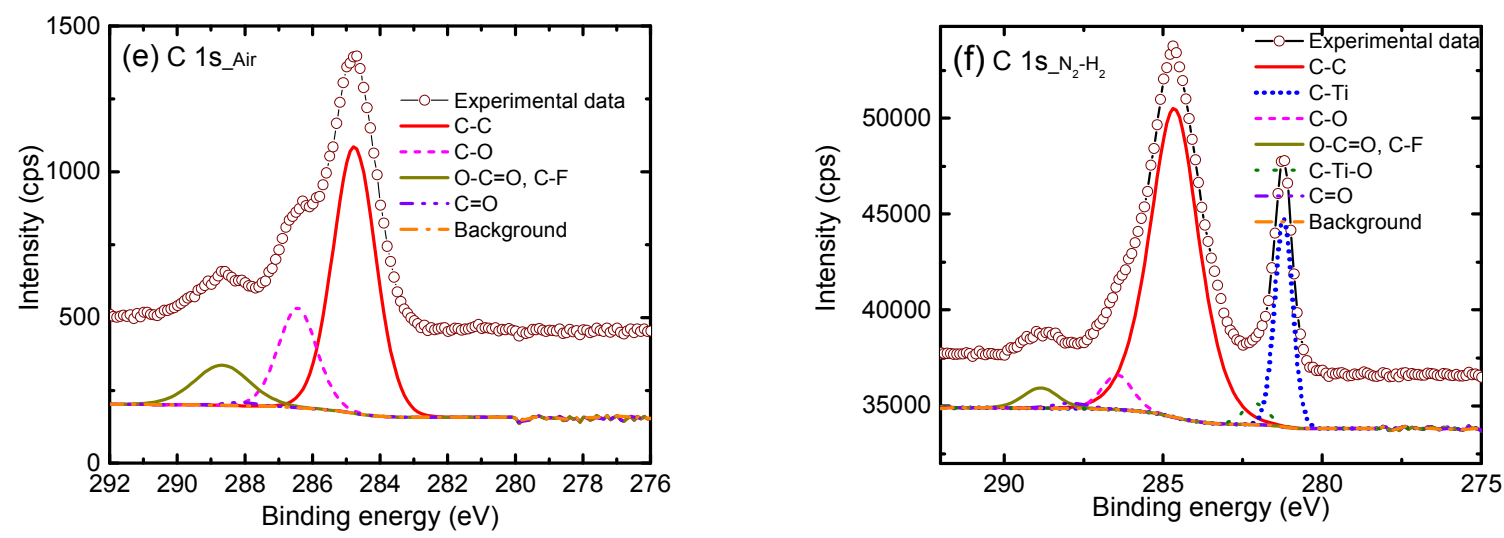

Figure 2: High resolution Ti2p spectra of (a) HF treated MAX phase, (b) Air annealed MXene and (c) $\mathrm{N}_{2} / \mathrm{H}_{2}$ annealed MXene and high resolution C1s spectra of (d) HF treated MAX phase, (e) Air annealed MXene and (f) $\mathrm{N}_{2} / \mathrm{H}_{2}$ annealed MXene.
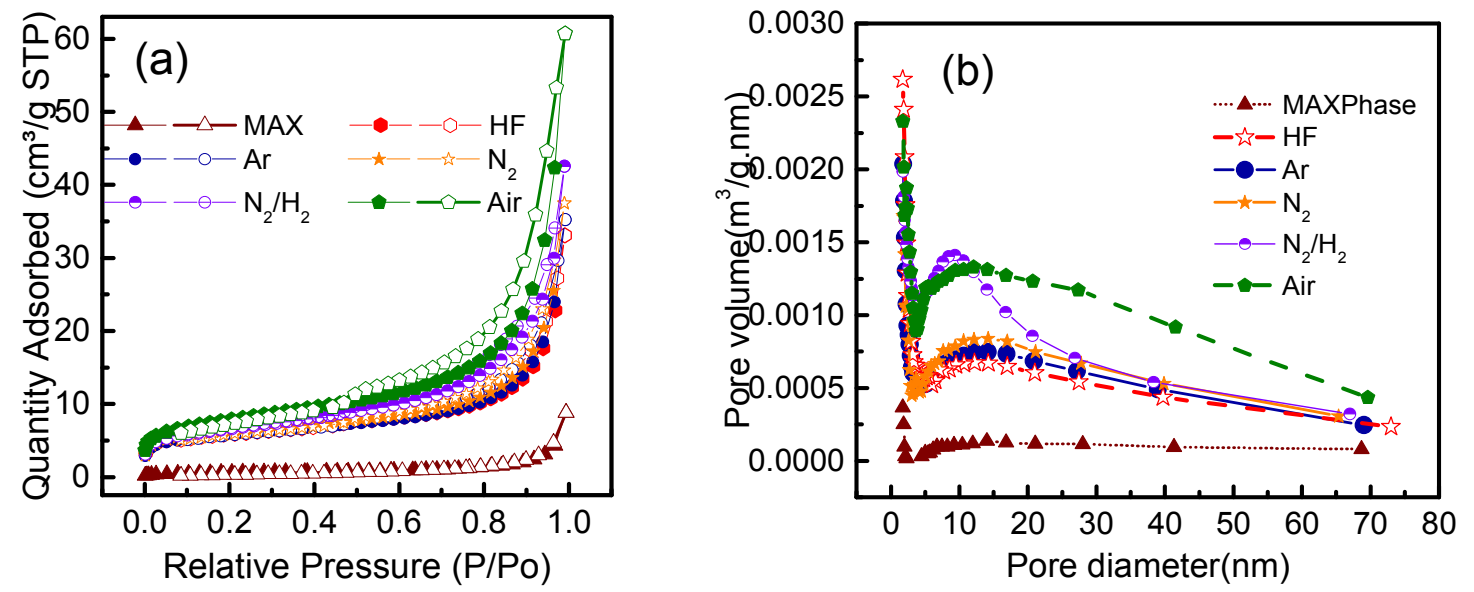

Figure 3: (a) Nitrogen adsorption and desorption isotherms and (b) Pore size distributions of different MXene samples. 

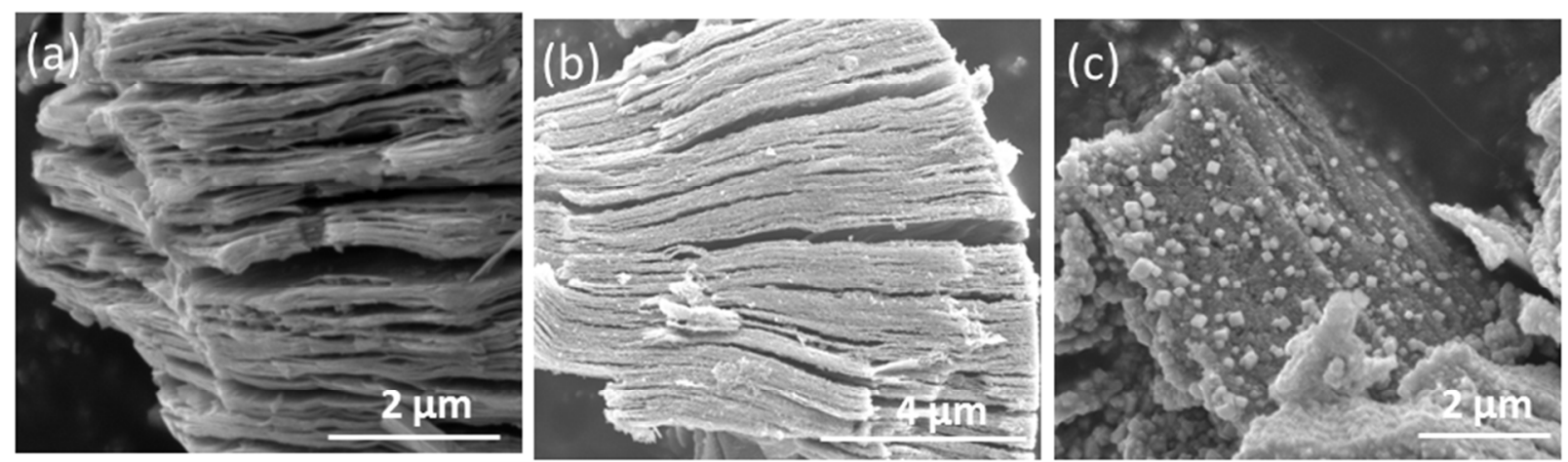

Figure 4: SEM images of (a) HF treated MAX Phase and MXene samples annealed in (b) $\mathrm{N}_{2} / \mathrm{H}_{2}$ atmosphere, and (c) air.
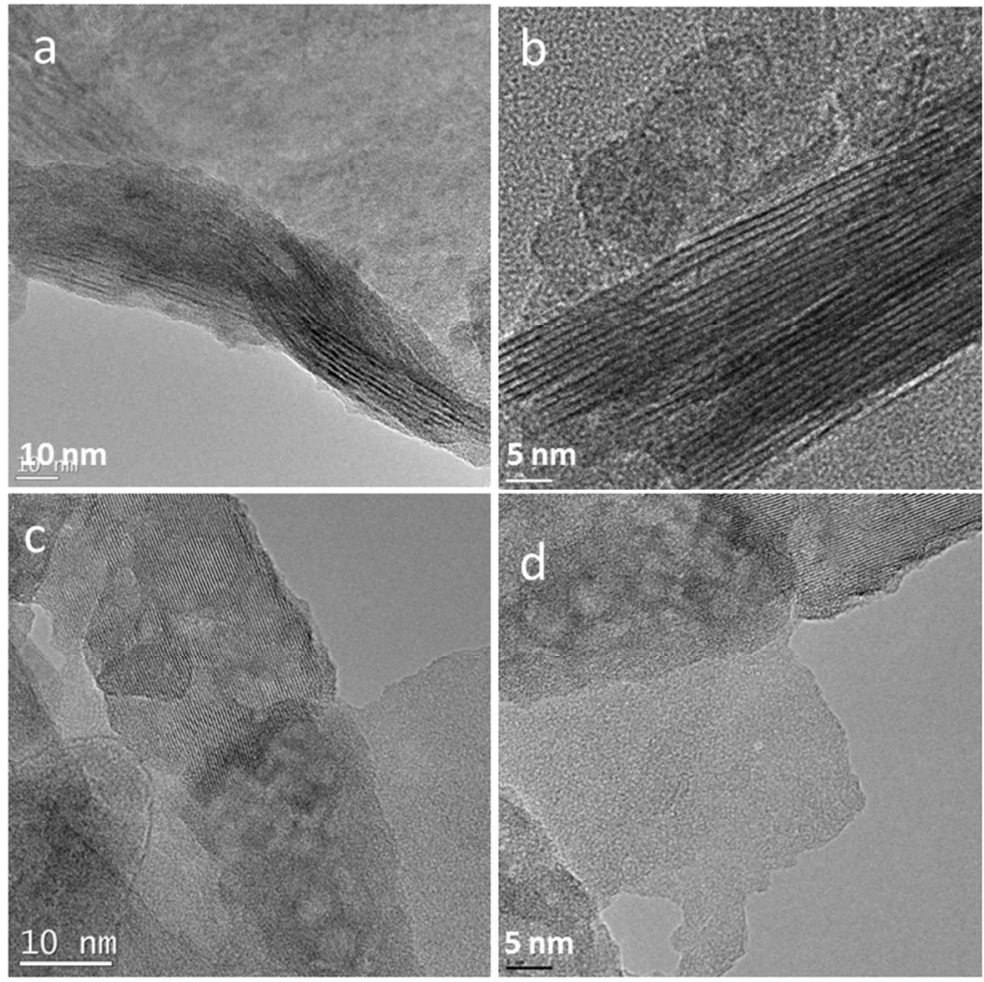

Figure 5: TEM images of (a) HF treated MAX Phase and MXene samples annealed in (b) Ar, (c) $\mathrm{N}_{2}$, and (d) $\mathrm{N}_{2} / \mathrm{H}_{2}$ atmosphere. 


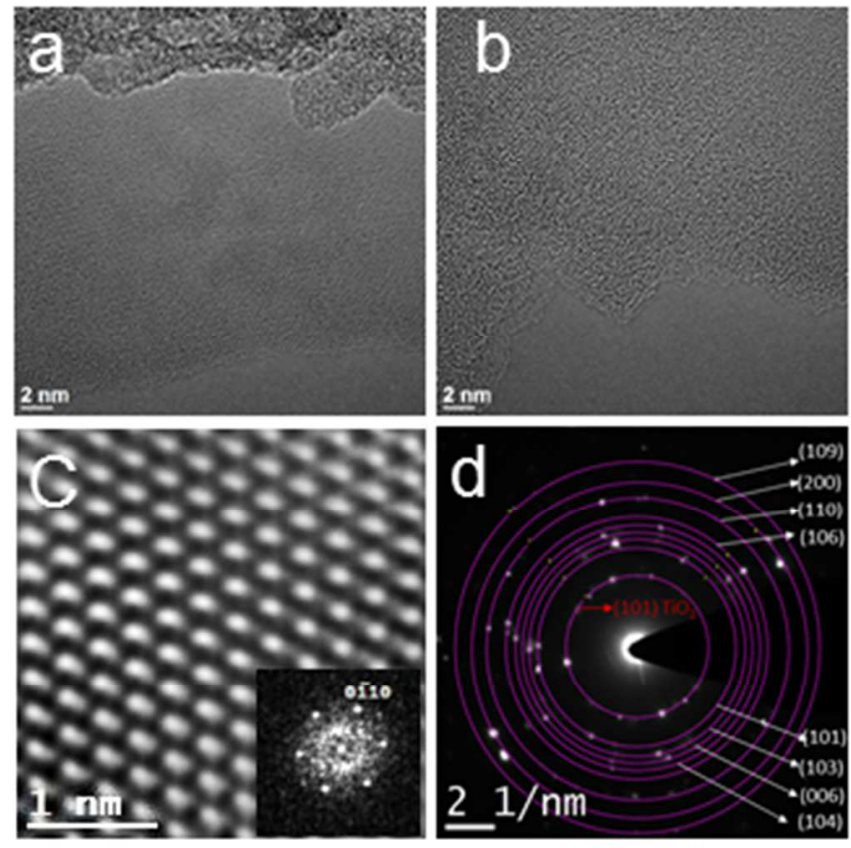

Figure 6: (a) \& (b) HRTEM images of etched MXene flakes, (c) Lattice resolved HRTEM image (Inset shows corresponding FFT pattern) and (d) Selected area electron diffraction patterns of MXene sample annealed in $\mathrm{N}_{2} / \mathrm{H}_{2}$ atmosphere. 

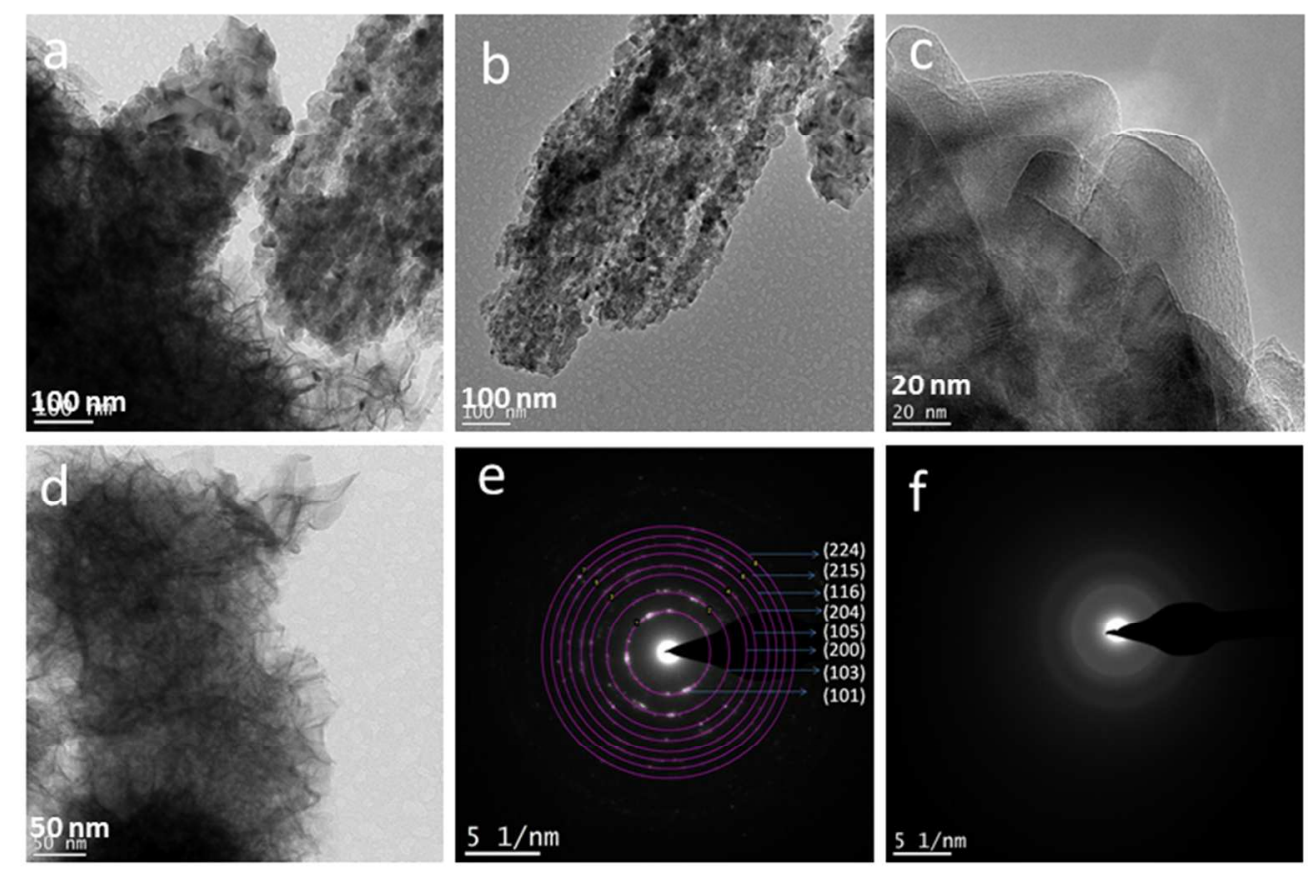

Figure 7: (a-d) TEM MXene sample annealed in air [(b) and (c) show nanocrystalline $\mathrm{TiO}_{2}$ particles and (d) shows graphitic carbon], SAED pattern of (e) nanocrystalline $\mathrm{TiO}_{2}$ and (f) graphitic carbon. 

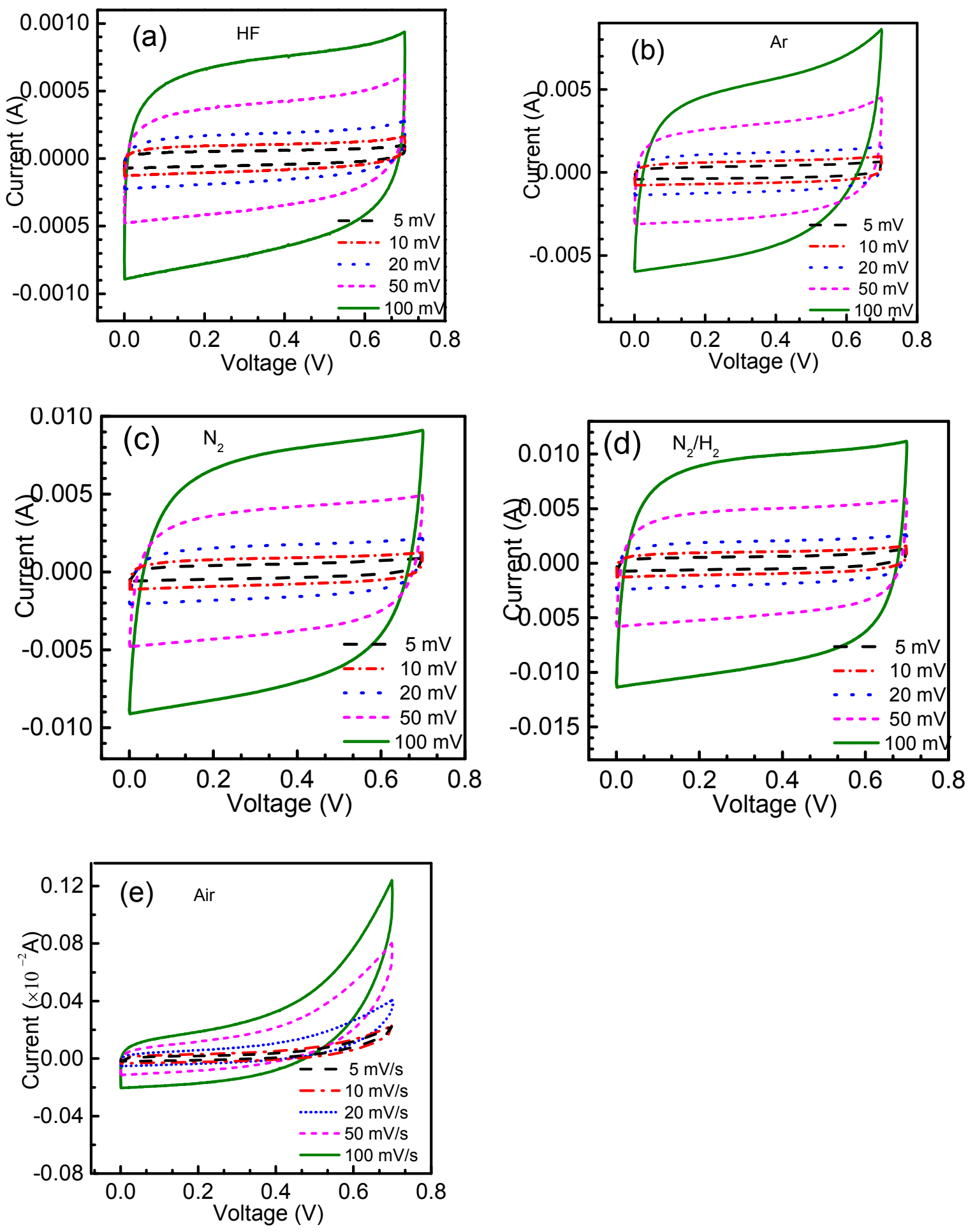

Figure 8: Cyclic voltammograms of symmetric supercapacitors based on (a) HF treated MAX Phase and MXene samples annealed in (b) Ar, (c) $\mathrm{N}_{2}$, (d) $\mathrm{N}_{2} / \mathrm{H}_{2}$, and (e) air atmosphere, at different scan rates. 

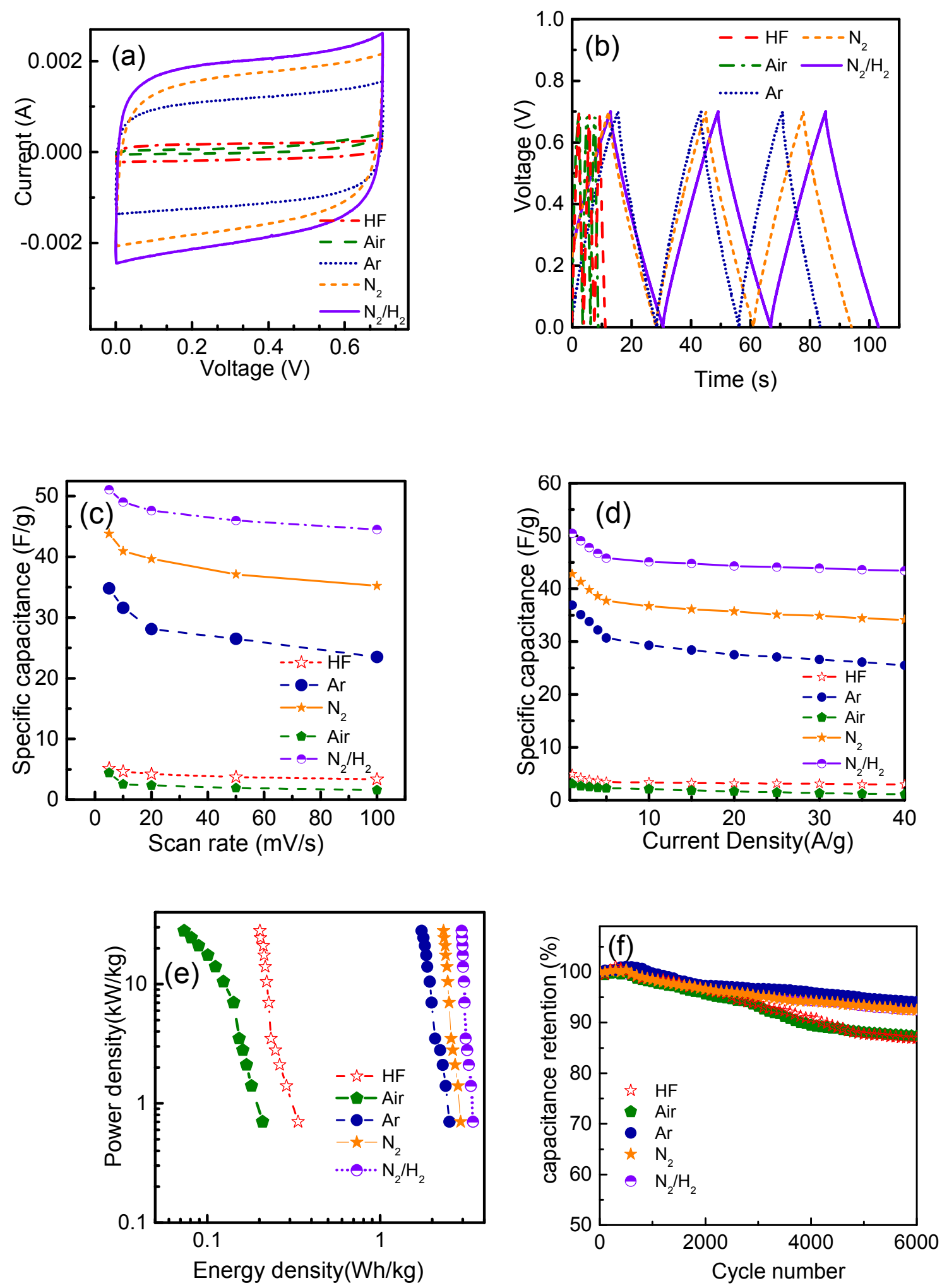
Figure 9: (a) Comparison of cyclic voltammograms of MXene samples at a scan rate of $20 \mathrm{mV} / \mathrm{s}$. (b) Comparison of galvanostatic charge-discharge curves of MXene samples at a constant current density of $1 \mathrm{~A} / \mathrm{g}$. Specific capacitances of MXene samples at different (c) scanrates and (d) current densities. (b) Ragone plot (power density vs. energy density) of MXene based symmetric supercapacitors. The energy densities and power densities were derived from the chargedischarge curves at different current densities. (f) Cycling performance of supercapacitors based on different MXene samples at a constant current density of $10 \mathrm{~A} / \mathrm{g}$ (6000 charge- discharge cycles).
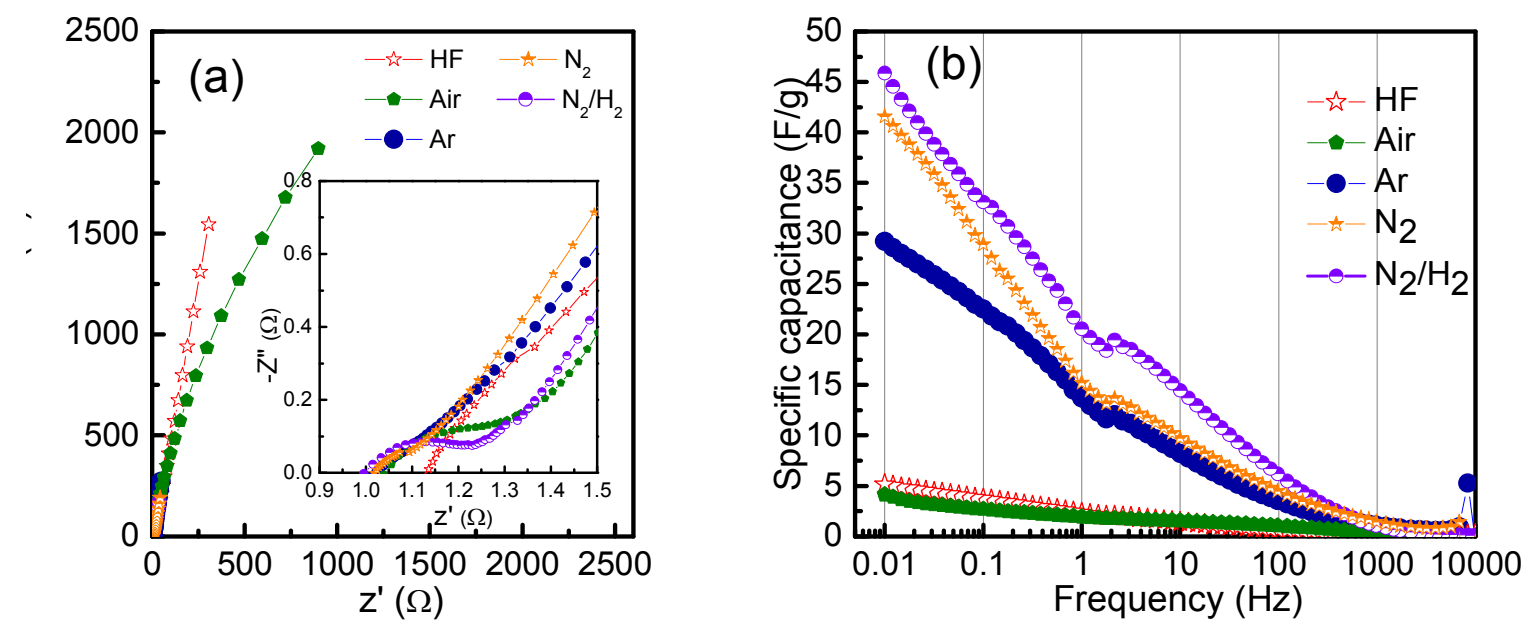

Figure 10: (a) Nyquist plots and (b) specific capacitance variation as a function of frequency, for supercapacitors based on MXene samples. 